\title{
DNA of Theileria orientalis, T. equi and $T$. capreoli in stable flies (Stomoxys calcitrans)
}

\author{
Sándor Hornok ${ }^{1 *} \mathbb{D}$, Nóra Takács', Sándor Szekeres ${ }^{1}$ Krisztina Szőke1, Jenő Kontschán², Gábor Horváth³ \\ and László Sugár ${ }^{4}$
}

\begin{abstract}
Background: From a veterinary-medical point of view, the stable fly, Stomoxys calcitrans, is perhaps the economically most important blood-sucking muscoid fly species (Diptera: Muscidae), owing to its worldwide occurrence, frequently high local abundance, direct harm caused to livestock, pet animals and humans, as well as its vector role. Considering the latter in the context of protozoan parasites, the stable fly is a mechanical vector of trypanosomes and Besnoitia besnoiti. However, its role as a vector of piroplasms appears to be seldom studied, despite old data suggesting mechanical transmission of babesiae by dipteran flies.

Methods: In this study 395 stable flies (and one Haematobia stimulans) were collected at a cattle farm with known history of bovine theileriosis, and at further nine, randomly chosen locations in Hungary. These flies were separated according to sex (30 of them also cut into two parts: the head with mouthparts and the thorax-abdomen), followed by individual DNA extraction, then screening for piroplasms by PCR and sequencing.

Results: In stable flies, Theileria orientalis and T. capreoli were identified at the cattle farm and T. equi was identified in three other locations. At the cattle farm, significantly more male stable flies carried piroplasm DNA than females. There was no significant difference between the ratio of PCR-positive flies between the stable (void of cattle for at least two hours) and the pen on the pasture with cattle at the time of sampling. Among dissected flies ( $29 \mathrm{~S}$. calcitrans and $1 \mathrm{H}$. stimulans), exclusively the thoracic-abdominal parts were PCR-positive, whereas the head and mouthparts remained negative.

Conclusions: Theileria DNA is detectable in stable flies, in the case of T. orientalis at least for two hours after bloodfeeding, and in the case of T. capreoli also in the absence of infected hosts (i.e. roe deer). Male flies rather than females, and thoracic-abdominal (most likely crop) contents rather than mouthparts may pose a risk of mechanical transmission. These data suggest that it is worth to study further the vector role of stable flies in the epidemiology of theilerioses, in which not the immediate, but rather the delayed type transmission seems possible.
\end{abstract}

Keywords: Muscidae, Blood-sucking, Mechanical vector, Male, Female, Gut, Diverticulum, Haematobia stimulans

\section{Introduction}

The stable fly, Stomoxys calcitrans, is a muscoid fly species (Diptera: Muscidae) with a worldwide distribution and increasingly recognized veterinary and medical

*Correspondence: Hornok.Sandor@univet.hu

1 Department of Parasitology and Zoology, University of Veterinary Medicine, Budapest, Hungary

Full list of author information is available at the end of the article significance [1]. Although stable flies attack a wide range of domestic and wild animals (including rats, guinea pigs, rabbits, monkeys, dogs, horses, camels, goats and pelicans), as well as humans, cattle are their main hosts [2]. Both sexes feed on blood, causing annoyance, blood loss and wounds [3]. Furthermore, Stomoxys flies are mechanical vectors of pathogens present in the blood and skin of their hosts, because in case of interrupted feeding, they 
can re-start their blood meal on another host [1]. When injecting saliva prior to blood-sucking, the stable fly can inoculate some infected blood remaining in its mouthparts [1]. Besides this immediate transmission, it was observed that stable flies may keep some blood in their crop (oesophageal diverticulum), which offers a friendly environment for pathogens that could be regurgitated during the next blood meal; thus a delayed transmission is also possible [1].

Among the pathogens known to be transmitted by stable flies, there are numerous economically significant viruses, rickettsiae and other bacteria. Considering protozoan parasites, the stable fly is a mechanical vector of trypanosomes and Besnoitia besnoiti [1]. Importantly, transmission experiments involving Trypanosoma evansi demonstrated a peculiar capacity of the stable fly for delayed transmission, in contrast to tabanids [1].

Piroplasms (Apicomplexa: Piroplasmida) are haemotropic protozoan parasites [4]. Among them, Babesia and Theileria species have soft and hard ticks (Acari: Ixodidae, Argasidae) as biological vectors, but old data also attest that blood-sucking flies, including members of the family Tabanidae and of the genus Stomoxys, can act as mechanical vectors in their transmission [4]. In particular, it has been demonstrated that members of the Theileria orientalis complex are capable of being mechanically transferred between cattle by intravenous inoculation with small volumes of blood [5] as well as by biting arthropods (by Tabanus trigeminus [6]; and by the sucking louse Linognathus vituli [7]). Despite of this, the role of stable flies in transmitting piroplasms appears to be seldom investigated.

In Hungary, the occurrence of T. orientalis has recently been demonstrated, but attempts to find the corresponding tick vector(s) failed so far [8]. This was the main reason for initiating the present study. In addition, when Babesia DNA was detected in the feces of bats, this was partly explained by the predominance of stable flies in the diet of some bat species [9], but the actual possibility of piroplasm carriage by these flies remains to be elucidated. Thus, the aims of the present study were to investigate: (i) if DNA of Babesia or Theileria is present in stable flies; (ii) if parasite DNA can also be detected in flies a few hours after their access to cattle or in the absence of nearby hosts (which could have provided infectious source); and (iii) to ascertain whether mouthpart-associated immediate or crop-associated delayed transmission is more likely.

\section{Methods}

\section{Sample collection}

Altogether 239 blood-sucking muscoid flies were collected at a cattle farm (Pásztó, 47 $55^{\prime} 34.5^{\prime \prime} \mathrm{N}, 19^{\circ} 40^{\prime} 49.8^{\prime \prime} \mathrm{E}$ in northern Hungary) with known occurrence of
Theileria orientalis, near the end of each month between August and October, 2017. At this location, flies were collected from 9:00 to 10:30 $\mathrm{h}$ at the main stable (from which all cattle were transferred to pens on the pasture before 7:00 h), and also in the pens near the cattle from 10:30 to 12:00 $\mathrm{h}$. The pen and pasture are at a distance of c. $0.5 \mathrm{~km}$ from the stable.

In addition, 157 blood-sucking muscoid flies were collected in further nine, randomly chosen locations (Fig. 1) with or without the presence of domestic or game animals (Table 1), between October 2017 and August 2019. Flies were caught with commercial fishing nets, and if intact, preserved in 70\% ethanol. Species identification (395 Stomoxys calcitrans and 1 Haematobia stimulans) and sexing was based on standard keys [10].

Flies were separated according to sex, disinfected on their surface with sequential washing for $15 \mathrm{~s}$ in three Petri dishes (containing 10\% sodium-hypochlorite, tap water or distilled water, respectively), then air-dried. Thirty flies were dissected into two parts (the head with the mouthparts and the thorax-abdomen) with sterile scalpel blades. These dissected flies included both males $(n=20)$ and females $(n=10)$, collected in the pen on pasture, in the middle of the main sampling period (September 2017) at the main site (No. 1 in Fig. 1).

\section{DNA extraction, PCR and sequencing}

DNA was extracted individually from each fly or their two parts, by using the QIAamp DNA Mini Kit (Qiagen, Hilden, Germany) according to the manufacturer's instructions, including an overnight digestion in tissue lysis buffer and $6.6 \%$ Proteinase $\mathrm{K}$ at $56{ }^{\circ} \mathrm{C}$. An extraction control $(100 \mu \mathrm{l}$ phosphate-buffered saline processed together with the samples) was also added to each set of 23 samples, for monitoring cross-contamination.

The conventional PCR used for the detection of piroplasms was modified from Casati et al. [11], as reported in Hornok et al. [12]. This method amplifies an approximately $500 \mathrm{bp}$ long fragment of the $18 \mathrm{~S}$ rRNA gene of Babesia and Theileria species with the primers BJ1 (forward: 5'-GTC TTG TAA TTG GAA TGA TGG-3') and BN2 (reverse: 5'-TAG TTT ATG GTT AGG ACT ACG3 '). Purification and sequencing of the PCR products were performed by Biomi Ltd. (Gödöllő, Hungary). Obtained sequences were manually edited, then aligned and compared to reference GenBank sequences by the BLASTn program (https://blast.ncbi.nlm.nih.gov). Representative sequences were submitted to the GenBank database under the accession numbers MN611176- MN611178.

\section{Statistical analysis}

Prevalence rates were compared with Fisher's exact test, and differences were considered significant if $P<0.05$. 


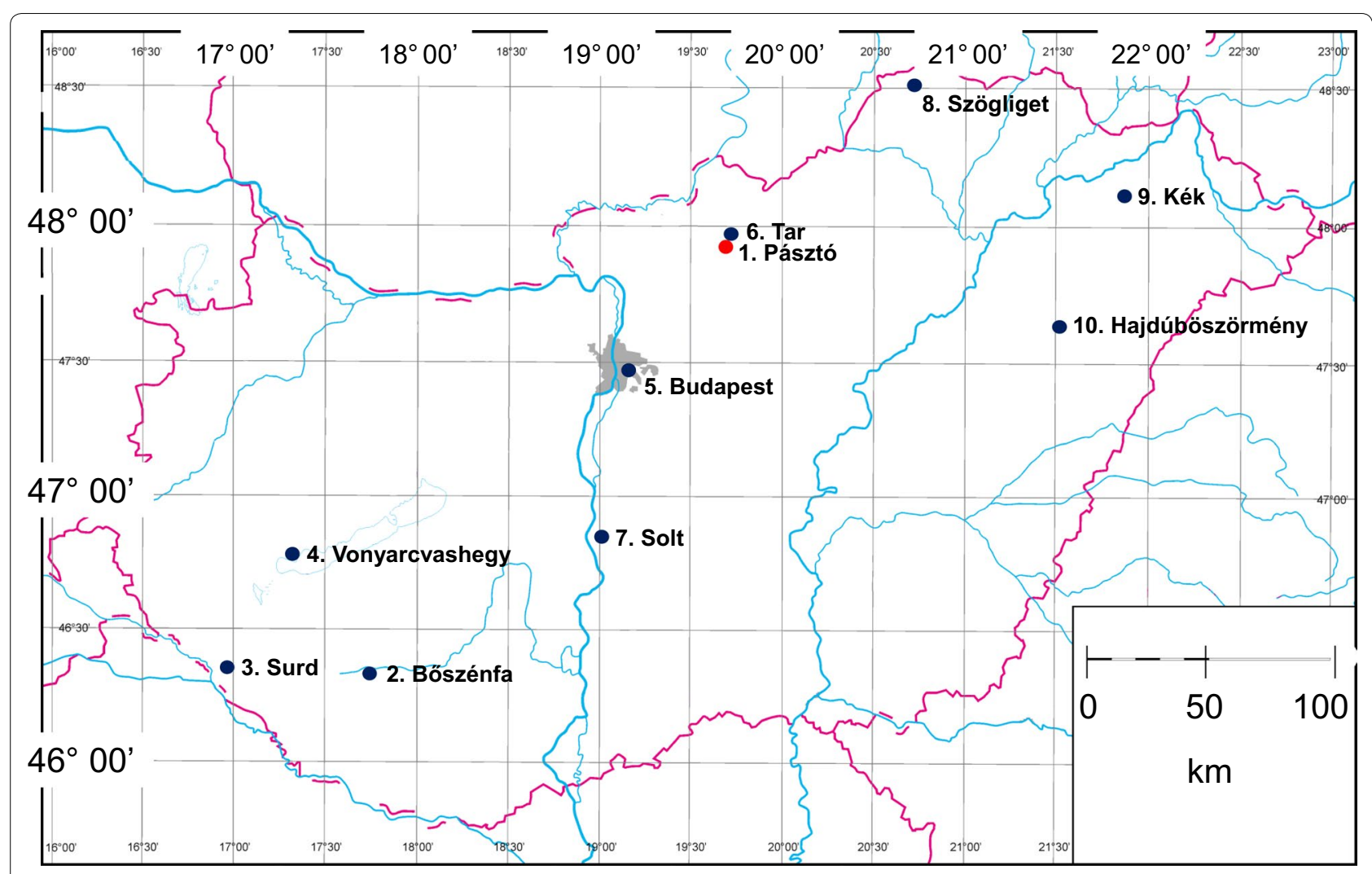

Fig. 1 Location, serial number and name of sampling sites. The red dot indicates the place of the cattle farm with repeated sampling

Table 1 Results of molecular analyses for piroplasm DNA in Stomoxys calcitrans according to collection site, month and sex

\begin{tabular}{|c|c|c|c|c|c|c|c|}
\hline \multirow[t]{2}{*}{ Locality } & \multirow[t]{2}{*}{ Habitat characteristics } & \multirow[t]{2}{*}{ Month } & \multicolumn{2}{|c|}{$\begin{array}{l}\text { PCR-positive among all } \\
\text { tested }\end{array}$} & \multicolumn{2}{|c|}{ Result of sequencing } & \multirow[t]{2}{*}{ GenBank ID } \\
\hline & & & Males & Females & Species $(n)$ & Identity (\%) & \\
\hline \multirow[t]{7}{*}{1} & \multirow[t]{3}{*}{ Stable (void of cattle for $>2 \mathrm{~h}$ ) } & August & $0 / 2$ & $1 / 14$ & T. orientalis $(1 \times)$ & 100 & MN611176 \\
\hline & & September & $20 / 55$ & $2 / 4$ & T. orientalis $(22 \times)$ & 100 & MN611176 \\
\hline & & October & $14 / 30$ & $15 / 45$ & T. orientalis $(29 x)$ & 100 & MN611176 \\
\hline & \multirow[t]{4}{*}{ Pen on pasture (with cattle) } & \multirow[t]{2}{*}{ August } & \multirow[t]{2}{*}{$1 / 2$} & \multirow[t]{2}{*}{$2 / 14$} & T. capreolia $(1 \times)$ & 100 & MN611178 \\
\hline & & & & & T. orientalis $(2 \times)$ & 100 & MN611176 \\
\hline & & September & $11 / 22$ & $2 / 10$ & T. orientalis $(13 \times)$ & 100 & MN611176 \\
\hline & & October & $14 / 31$ & $5 / 9$ & T. orientalis $(19 \times)$ & 100 & MN611176 \\
\hline 2 & Farm with horses, game & October & $0 / 2$ & $2 / 21$ & T. equi $(2 \times)$ & 100 & MN611177 \\
\hline 3 & Farm with cattle & October & $0 / 3$ & $0 / 5$ & - & - & - \\
\hline 4 & Lake shore (beach) & August & $0 / 1$ & $0 / 3$ & - & - & - \\
\hline 5 & Garden (in capital city) & November & $0 / 1$ & - & - & - & - \\
\hline 6 & Garden (in a village) & September & $0 / 1$ & - & - & - & - \\
\hline 7 & $\begin{array}{l}\text { Livestock reserve with horses and } \\
\text { ruminants }\end{array}$ & June & $1 / 25$ & $0 / 59$ & T. equi $(1 \times)$ & 100 & MN611177 \\
\hline 8 & Garden with a horse & July & $1 / 4$ & $1 / 5$ & T. equi $(2 x)$ & 100 & MN611177 \\
\hline 9 & Garden (in a village) & September & $0 / 2$ & - & - & - & - \\
\hline 10 & Garden (in a village) & September & $0 / 17$ & $0 / 8$ & - & - & - \\
\hline
\end{tabular}

a Isolate "capreoli-CE1" (KY308178) 


\section{Results}

Piroplasms in stable flies at the cattle farm (locality 1)

From August to October $36.6 \%$ of stable flies (87/238) were PCR-positive for piroplasms (Table 1). Males carried piroplasm DNA significantly more frequently than females (60 of 142 vs 27 of 96, respectively; $P=0.028$ ). Compared to August, the ratio of PCR-positive flies was significantly higher both in September (4 of 32 vs 35 of 91, respectively; $P=0.008$ ) and in October ( 4 of 32 vs 48 of 115 , respectively; $P=0.002$ ). However, there was no significant difference in the ratio of PCR-positive flies between the stable (void of cattle) and the pen on the pasture with cattle at the time of sampling (52 of $150 \mathrm{vs}$ 35 of $88 ; P=0.48$; Table 1$)$. In addition, the single specimen of Haematobia stimulans was also PCR-positive for piroplasms.

Considering dissected flies (29 S. calcitrans and $1 \mathrm{H}$. stimulans), in all cases exclusively the body (thoracicabdominal part) of flies was PCR-positive, whereas the head and mouthparts remained negative. This was a highly significant association $(P<0.0001)$.

Sequencing identified $T$. orientalis in the majority (86 of 87) of the PCR-positive samples (Table 1), with $100 \%(432 / 432 \mathrm{bp})$ identity to the previously published sequence from this location (GenBank: KT725847). One sample contained DNA of $T$. capreoli isolate "capreoli CE-1", with $100 \%$ (440/440 bp) identity to its sequence reported from Hungary (GenBank: KY308178).

\section{Piroplasms in stable flies from randomly chosen locations (localities 2-10)}

Only 3.2\% (5 of 157) of randomly collected stable flies were PCR-positive for piroplasms (Table 1). All these positive samples originated from places with horses nearby and contained DNA of $T$. equi, with $100 \%$ (303/303 to $437 / 437 \mathrm{bp}$ ) identities to previously reported sequences from Hungary (GenBank: JX4578282), Ukraine (GenBank: KP868757) and Switzerland (GenBank: KM046919, KM046920).

\section{Discussion}

To our knowledge, this is the first account on the detection of T. capreoli, T. equi and T. orientalis DNA in Stomoxys calcitrans. Relevant to these results, biting flies were found negative for T. orientalis in Australia in a previous study [13], whereas mosquitoes were reported to carry this piroplasm in the UK [14]. Unexpectedly, no association was found between tick or stable fly infestation of horses and their T. equi seropositivity in Brazil [15].

Considering the preparation of stable flies for molecular analysis in this study, surface disinfection must have effectively removed the blood, which possibly contaminated the mouthparts outside. In addition, we hypothesize that the survival rate of a protozoan parasite (sensitive to desiccation) should be very low on such a surface. On the other hand, surface disinfection could not completely clear the inside/contents of tubular mouthparts, which remained always PCR-negative in this study. In line with this, it was postulated that the survival time of a protozoan parasite is probably very short even within the mouthparts of S. calcitrans [16]. Therefore, based on the present results (i.e. T. orientalis DNA absent in the head and mouthparts, but restricted to the thoracic-abdominal part of the flies), mouthpart-associated immediate transmission of theileriae by Stomoxys appears to be significantly less likely, than delayed transmission via regurgitated crop contents. This is in line with previous observations that the stable fly has a peculiar capacity for the delayed transmission of another protozoan parasite, Trypanosoma evansi [1].

The source of piroplasm DNA in the thorax-abdomen (as observed here) is supposed to be, at least partly, the diverticulum (crop) of stable flies, involved in regurgitation. In general, during the feeding of muscoid flies fluids that are dilute (e.g. blood) are shunted for temporary storage to the diverticulum; then, contents of the diverticulum from the previous blood meal are regurgitated through the proboscis into the feeding substrate [17]. Experimental evidence has shown that stable flies, in particular, will direct some of the ingested blood into their crop, where it can stay 24 hours or more [1]. Pathogens may survive longer in the crop than in the gut, because it is a more friendly environment devoid of digestive secretions [1]. Stable flies will then regurgitate part of the previous blood meal during the early phase of the next blood meal, before taking up a new one [18]. The volume of blood regurgitated by $S$. calcitrans is up to $0.18 \mu \mathrm{l}$ [19], which (based on normal values of cattle) may contain more than $10^{6}$ bovine red blood cells. Thus, regurgitation of a relatively high amount of the previous blood meal could be an important way of transmitting high doses of disease agents [1].

Although the volume of ingested blood does not show significant difference between the sexes [20], females typically ingest blood meals an average of 1.8 times per day, and males 2.8 times per day [21]. This may explain why male stable flies of the present study carried piroplasm DNA significantly more frequently, implying that their suspected mechanical vector role (if any) may also surpass that of females.

There was no difference between the rate of PCR positivity among flies in the stable (which was void of cattle for at least two hours) and the pen on the pasture (where the animals were present at the time of sampling). This implies that PCR positivity did not 
depend on the presence of cattle next to the flies (i.e. on fresh blood meal). This was confirmed by finding one T. capreoli-positive sample, without roe deer on the pasture (and knowing that cattle are not susceptible to the roe-deer specific isolate "capreoli-CE1" detected here [22]). On the other hand, the low level of T. equi positivity in case of randomly collected samples suggests that the (former or nearby) presence of infected, piroplasm carrier animals is a prerequisite for any risks associated with the suspected vector role of stable flies.

Regarding the three Theileria species detected in $S$. calcitrans, T. equi is known to be transmitted mechanically via needles/syringes not exchanged between horses during blood sampling [23]. Members of the $T$. orientalis complex can also be transmitted mechanically through the inoculation of infected blood [5] or via horse flies [6] and biting lice [7]. It was suggested that further blood-sucking arthropod vectors of $T$. orientalis might exist, including biting flies [24], and stable flies in particular [25]. The chances of this is further enhanced by the generally long-term persistence of theileriae in the blood stream [26], similarly to another intra-erythrocytic bovine pathogen, Anaplasma marginale, of which ticks are biological vectors, but which may also have stable flies as mechanical vectors [27].

Results of the present study also reflected identity of all obtained $T$. orientalis sequences, and local genetic homogeneity of $T$. orientalis is thought to be interrelated with the absence of sexual recombination in ticks as biological vectors, i.e. the predominance of mechanical transmission [5]. Haemaphysalis punctata is the most likely tick vector of the T. orientalis complex in Europe and Hungary [12]. Larvae and nymphs of this tick species do not typically infest cattle [28, 29], thus their substantial role in the transstadial transmission, characteristic of theileriae, cannot be postulated. This raises the possibility and "ecological need" of T. orientalis for alternative modes of vector-borne transmission, most likely by blood-sucking flies.

\section{Conclusions}

Theileria DNA is detectable in stable flies, in case of T. orientalis at least for two hours after blood-feeding, and in case of $T$. capreoli also in the absence of infected hosts (i.e. roe deer). Male flies rather than females, and thoracic-abdominal (most likely crop) contents rather than mouthparts may pose a risk of mechanical transmission. These data suggest that it is worth to study further the vector role of stable flies in the epidemiology of theilerioses, in which not the immediate, but rather the delayed transmission type seems possible.

\section{Acknowledgements}

The authors thank the contributions by the staff at the Ondrésik cattle farm in Pásztó. The open access publication was supported by the European Union and co-financed by the European Social Fund (grant agreement no. EFOP3.6.3-VEKOP-16-2017-00005, project title: Strengthening the scientific replacement by supporting the academic workshops and programs of students, developing a mentoring process).

\section{Authors' contributions}

SH designed the study, collected some of the samples, supervised molecular phylogenetic analyses and wrote the manuscript. KSZ and SS extracted the DNA. JK, GH and LS provided indispensable samples. NT performed molecular analyses. All authors read and approved the final manuscript.

\section{Funding}

Molecular work was supported by NKFI K 130216

\section{Availability of data and materials}

The sequences obtained and/or analyzed during the present study are deposited in the GenBank database under the accession numbers MN611176MN611178. All other relevant data are included in the article; raw data are available upon request.

\section{Ethics approval and consent to participate}

Not applicable. No vertebrate animals were caught or restrained for fly collection, therefore no ethical approval was needed.

\section{Consent for publication}

Not applicable.

\section{Competing interests}

The authors declare that they have no competing interests.

\section{Author details}

${ }^{1}$ Department of Parasitology and Zoology, University of Veterinary Medicine, Budapest, Hungary. ${ }^{2}$ Plant Protection Institute, Centre for Agricultural Researches, Budapest, Hungary. ${ }^{3}$ Veterinary Authority, Csurgó, Hungary. ${ }^{4}$ Department of Game Management and Ethology, Faculty of Agricultural and Environmental Sciences, University of Kaposvár, Kaposvár, Hungary.

Received: 2 November 2019 Accepted: 26 March 2020

Published online: 09 April 2020

\section{References}

1. Baldacchino F, Muenworn V, Desquesnes M, Desoli F, Charoenviriyaphap T, Duvallet G. Transmission of pathogens by Stomoxys flies (Diptera, Muscidae): a review. Parasite. 2013;20:26.

2. Showler AT, Osbrink WL. Stable fly, Stomoxys calcitrans (L.), dispersal and governing factors. Int J Insect Sci. 2015;7:19-25.

3. Yeruham I, Braverman Y. Skin lesions in dogs, horses and calves caused by the stable fly Stomoxys calcitrans (L.) (Diptera: Muscidae). Rev Elev Med Vet Pays Trop. 1995:48:347-9.

4. Friedhoff KT. Transmission of Babesia: other means of transmission. In: Ristic M, editor. Babesiosis of domestic animals and man. Boca Raton: CRC Press; 1988.

5. Hammer JF, Jenkins C, Bogema D, Emery D. Mechanical transfer of Theileria orientalis: possible roles of biting arthropods, colostrum and husbandry practices in disease transmission. Parasit Vectors. 2016;9:34.

6. Takahashi K, Wada A, Kawai S, Yokota H, Kurosawa T, Sonoda M. Investigations of isolation, transmission and virulence of bovine Babesia sp. in Hokkaido. J College Dairying. 1983;10:171-81.

7. Fujisaki K, Kamio T, Kawazu S, Shimizu S, Shimura K. Theileria sergenti experimental transmission by the long-nosed cattle louse, Linognathus vituli. Ann Trop Med Parasitol. 1993:87:217-8.

8. Hornok S, Takács N, Kontschán J, György Z, Micsutka A, Iceton S, et al. Diversity of Haemaphysalis-associated piroplasms of ruminants in centraleastern Europe, Hungary. Parasit Vectors. 2015;8:627.

9. Hornok S, Estók P, Kováts D, Flaisz B, Takács N, Szőke K, et al. Screening of bat faeces for arthropod-borne apicomplexan protozoa: Babesia canis 
and Besnoitia besnoiti-like sequences from Chiroptera. Parasit Vectors. 2015;8:441.

10. Sztankay-Gulyás M. Muscidae in Hungary and the surrounding areas. Acta Vet Acad Sci Hun. 1953;3:245-86.

11. Casati S, Sager H, Gern L, Piffaretti JC. Presence of potentially pathogenic Babesia sp. for human in Ixodes ricinus in Switzerland. Ann Agric Environ Med. 2006;13:65-70.

12. Hornok S, Mester A, Takács N, Fernández de Mera IG, de la Fuente J, Farkas R. Re-emergence of bovine piroplasmosis in Hungary: has the etiological role of Babesia divergens been taken over by B. major and Theileria buffeli? Parasit Vectors. 2014;7:434.

13. Hammer JF, Emery D, Bogema DR, Jenkins C. Detection of Theileria orientalis genotypes in Haemaphysalis longicornis ticks from southern Australia. Parasit Vectors. 2015:8:229.

14. Fernández de Marco M, Brugman VA, Hernández-Triana LM, Thorne L, Phipps LP, Nikolova NI, et al. Detection of Theileria orientalis in mosquito blood meals in the United Kingdom. Vet Parasitol. 2016;229:31-6.

15. Dos Santos TM, Roier EC, Santos HA, Pires MS, Vilela JA, Moraes LM, et al. Factors associated to Theileria equi in equids of two microregions from Rio de Janeiro, Brazil. Rev Bras Parasitol Vet. 2011:20:235-41.

16. Bigalke RD. New concepts on the epidemiological features of bovine besnoitiosis as determined by laboratory and field investigations. Onderstepoort J Vet Res. 1968;35:3-137.

17. Moon RD. Muscid flies (Muscidae). In: Mullen G, Durden L, editors. Medical and veterinary entomology. 3rd ed. Cambridge: Academic Press; 2019. p. 345-68.

18. Butler JF, Kloft WJ, Dubose LA, Kloff ES. Recontamination of food after feeding a ${ }^{32} \mathrm{P}$ food source to biting Muscidae. J Med Entomol. 1977;27:874-7.

19. Kloft WJ. Radioisotopes in vector research. In: Harris KF, editor. Advances in disease vector research, vol. 9. New York: Springer; 1992. p. 41-66.

20. Salem A, Franc M, Jacquiet P, Bouhsira E, Liénard E. Feeding and breeding aspects of Stomoxys calcitrans (Diptera: Muscidae) under laboratory conditions. Parasite. 2012;19:309-17.
21. Harris RL, Miller JA, Frazer ED. Horn flies and stable flies feeding activity. Ann Entomol Soc Am. 1974;67:891-4.

22. Hornok S, Sugár L, Horváth G, Kovács T, Micsutka A, Gönczi E, et al. Evidence for host specificity of Theileria capreoli genotypes in cervids. Parasit Vectors. 2017;10:473.

23. Gerstenberg C, Allen WR, Phipps LP. The mechanical transmission of Babesia equi infection in a British herd of horses. In: Werner U, Wade DF, Mumford JA, Kaaden OR, editors. Proceedings of the Eighth International Conference on Equine Infectious Diseases, Dubai, United Arab Emirates, March 23-26 1998. Newmarket (UK): R \& W Publications Ltd.; 1998. p. 100.

24. Heath ACG. The role of ticks, biting flies and lice in the transmission of theilerosis. Vet Script. 2013;26:13-4.

25. Yam J, Bogema DR, Jenkins C. Oriental theileriosis. Ticks Tick Borne Pathog. 2018;vol:1-31.

26. Mans BJ, Pienaar R, Latif AA. A review of Theileria diagnostics and epidemiology. Int J Parasitol Parasites Wildl. 2015;4:104-18.

27. Scoles GA, Broce AB, Lysyk TJ, Palmer GH. Relative efficiency of biological transmission of Anaplasma marginale (Rickettsiales: Anaplasmataceae) by Dermacentor andersoni (Acari: Ixodidae) compared with mechanical transmission by Stomoxys calcitrans (Diptera: Muscidae). J Med Entomol. 2005;42:668-75.

28. Akimov I, Nebogatkin I. Distribution of the tick Haemaphysalis punctata (Acari, Ixodidae) in Ukraine. Vestn Zool. 2012;46:46-51.

29. Pfäffle MP, Santos-Silva MM, Jaenson TGT, Vatansever Z, Petney TN. Haemaphysalis punctata Canestrini and Fanzago, 1878. In: Estrada-Peña A, Mihalca AD, Petney TN, editors. Ticks of Europe and North Africa: a guide to species identification. Berlin: Springer International Publishing; 2017. p. $237-42$.

\section{Publisher's Note}

Springer Nature remains neutral with regard to jurisdictional claims in published maps and institutional affiliations. 